\title{
El mercado del biodiésel y las políticas públicas: Comparación de los casos argentino y brasileño
}

\author{
Georges Gérard Flexor, Karina Yoshie Martins Kato y \\ Marina Yesica Recalde
}

En este trabajo se analiza comparativamente el desarrollo del mercado del biodiésel en la Argentina y el Brasil, atendiendo a los aspectos institucionales de la formulación de la política y sus repercusiones. El estudio se efectuó mediante un análisis del proceso de formulación de las políticas, junto con una discusión sobre su impacto al examinar la información estadística. Entre los resultados se destacan las divergencias en los objetivos de la política en ambos países. En el caso argentino ha sido relevante el problema del abastecimiento de gasóleo, mientras que en el Brasil resaltan los objetivos de promoción de la agricultura familiar. Asimismo, en el caso brasileño se observan la importancia de la empresa Petróleo Brasileiro (PETROBRAS) y algunas deficiencias en el alcance de los objetivos; mientras que en el caso argentino se aprecia que el mercado externo continúa siendo el motor de la industria.

PALABRAS CLAVE

CLASIFICACIÓN JEL

AUTORES
Energía de la biomasa, combustibles diésel, política de desarrollo, mercados, sector agroindustrial, análisis comparativo, Argentina, Brasil

Q48, Q42, O54

Georges Gérard Flexor es profesor adjunto del Instituto Multidisciplinario de la Universidad Federal Rural de Río de Janeiro (ufrrj), Programa de Posgrado de Ciencias Sociales en Desarrollo, Agricultura y Sociedad (CPDA)/ufrRJ, Instituto Nacional de Ciencia y Tecnología en Políticas Públicas, Estrategias y Desarrollo (INCT/PPED).gflexor@gmail.com

Karina Yoshie Martins Kato es doctoranda del Programa de Posgrado de Ciencias Sociales en Desarrollo, Agricultura y Sociedad de la Universidad Federal Rural de Río de Janeiro (UFRRJ). anirakato@yahoo.com

Marina Yesica Recalde es investigadora posdoctoral del Consejo Nacional de Investigaciones Científicas y Técnicas (CONICET) y del Departamento de Economía de la Universidad Nacional del Sur (UNs).mrecalde@uns.edu.ar 


\section{I}

\section{Introducción}

Si bien los orígenes del biodiésel se remontan a finales del siglo XIX, su desarrollo ha cobrado mayor impulso en las últimas décadas y el debate se ha tornado aún más importante y controversial en los últimos años a raíz de una conjunción de factores.

El propósito de este artículo es presentar las políticas de desarrollo del biodiésel en la Argentina y el Brasil. Su interés obedece a que ambos países han implementado recientemente políticas de promoción del biodiésel y ya se están posicionando como grandes productores y consumidores mundiales. Desde el punto de vista de los autores, el aporte de este trabajo radica en que de él pueden desprenderse relevantes conclusiones en torno de la importancia de la institucionalidad en el desarrollo de la política de promoción de los biocombustibles y los resultados obtenidos. Las conclusiones pueden constituir una valiosa herramienta de diagnóstico para la elaboración de la política energética en países con características similares. Además, permiten observar la posición de estos dos países en el contexto de una evolución del sistema energético global hacia fuentes más renovables.

La metodología de análisis se basa en la comparación de las motivaciones originales de las políticas, los procesos de formulación y los resultados alcanzados en la promoción del biodiésel en la Argentina y el Brasil ${ }^{1}$. Para

$\square$ Este trabajo fue realizado en el CPDA/UFRRJ, en el marco de un convenio de intercambio entre el Departamento de Economía de la Universidad Nacional del Sur (UNS) y el CPDA de la Universidad Federal Rural de Río de Janeiro.

1 Entre las variables propuestas en el estudio se encuentran la evolución del consumo de gasóleo o aceite diésel, la participación relativa de dicho combustible en el consumo total del sector transporte, la evolución de la producción de soja orientada a la producción de biodiésel, la evolución de las exportaciones de biodiésel en cada país, la participación de las familias en la producción de insumos para el biodiésel y la concentración en la propiedad de la tierra. Las fuentes de información utilizadas son las bases de datos del estos fines, el estudio se estructura en cuatro secciones luego de esta Introducción. En la sección II se presenta la estructura que sostiene el análisis comparativo de las políticas de promoción del biodiésel en ambos países. En la sección III se examinan las características iniciales y la relevancia de los factores impulsores en cada caso, poniéndose en evidencia dos mecanismos impulsores de las políticas: los incentivos de los mercados externos, que son muy importantes en el caso argentino, y las agendas políticas del ejecutivo en el caso brasileño. En segundo lugar, se estudia el proceso de formulación de las políticas de promoción en cada país, atendiendo a los impulsores y los distintos agentes que han participado en forma activa intentando promover sus intereses dentro del marco institucional. En la sección IV se presentan las características básicas de las leyes de promoción y los instrumentos utilizados. La descripción del proceso de formulación y de los instrumentos adoptados en cada país resalta la importancia de las instituciones y de los actores en el proceso de formulación de las políticas del biodiésel. En tal sentido, se enfatizan los factores endógenos de dicho proceso de formulación. Se analizan además las repercusiones de la puesta en marcha de la legislación en distintas dimensiones, atendiendo a los objetivos que esta se ha propuesto en cada caso. En esta sección resaltan las consecuencias productivas y distributivas de las políticas. Por último, se presentan las reflexiones finales en forma comparada.

Sistema de Información Económica Energética (SIEE)/Organización Latinoamericana de Energía (OLADE), de la Agencia Nacional de Petróleo, Gas Natural y Biocombustibles (ANP) del Ministerio de Desarrollo Agrario del Banco Mundial, e información provista por el Ministério de Minas e Energía (MME) del Brasil y la Secretaría de Energía de la Argentina. 


\section{II \\ Componentes para el análisis del desarrollo del biodiésel}

Los resultados alcanzados por cada una de las políticas públicas desarrolladas en los distintos países para promover la penetración del biodiésel dependen en gran medida de sus objetivos y de las características de los países, pero fundamentalmente de los factores políticoinstitucionales en el momento del diseño. En este sentido, es fundamental tener en cuenta los componentes principales de la evaluación de los senderos del desarrollo de biocombustibles, los que son fundamentales para el desarrollo de este artículo.

En el gráfico 1 se presentan esquemáticamente los distintos bloques que se enfrentan en el momento de analizar el desarrollo de las políticas de promoción de los biocombustibles y su desempeño. Tal como se puede observar, la formulación de las políticas de biocombustibles se encuentra determinada en forma directa por un conjunto de condicionantes externos que establecen su dirección en forma exógena. Al mismo tiempo, existe un impacto bidireccional con la estructura institucional del país, puesto que esta determina el tipo de instrumentos utilizados para la promoción de los biocombustibles, y posteriormente a la formulación de las políticas ellas mismas determinan en cierta forma la estructura institucional. Finalmente, el bloque de resultados comprende los impactos sobre las distintas dimensiones a las que se ha pretendido afectar en forma directa con la formulación de las políticas, así como respecto de aquellas que se afectan en forma indirecta. Dado que la formulación de las políticas es una cuestión dinámica, este último bloque influirá en la formulación de las políticas en forma de retroalimentación.

Las motivaciones que han impulsado al biodiésel con mayor intensidad han sido diversas. Entre las principales se destacan las motivaciones energéticas, relacionadas con la búsqueda de la seguridad energética, la independencia geopolítica, y el impacto de la volatilidad de los precios del petróleo (Khanna M., Scheffran J. \& Zilberman D., 2006). La motivación medioambiental, relacionada con la búsqueda de reducir las emisiones de gases de efecto de invernadero (GEI), es otro factor determinante del desarrollo de los biocombustibles. La formulación de políticas de promoción del biodiésel en la Unión Europea, por ejemplo, fue en parte impulsada por el intento público de limitar las GEI (Bureau y otros, 2006; Timilsina y Shrestha, 2011). Las oportunidades agrícolas, relacionadas con el desenvolvimiento de la actividad, la promoción del empleo, la utilización de tecnologías de punta y

GRÁFICO 1

Bloques de análisis

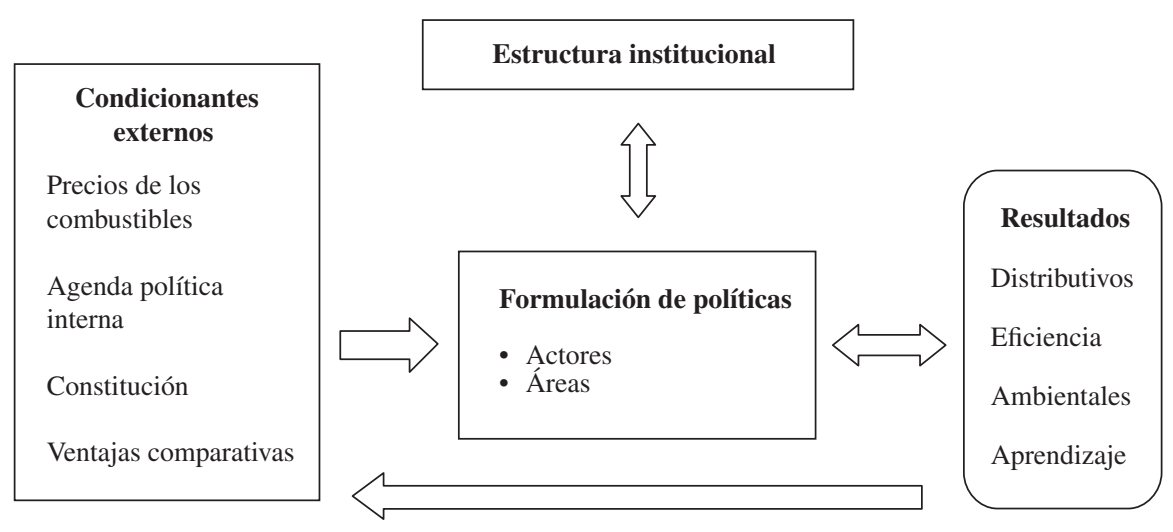

Fuente: elaboración propia. 
la comercialización de los insumos y los productos, constituye también un aspecto fundamental del procesamiento de los biocombustibles (Pistonesi y otros, 2008). Y para los países en desarrollo que presentan ventajas comparativas en la producción de bienes intensivos en recursos naturales, los biocombustibles ofrecen una oportunidad de inserción internacional estratégica (Msangi, Ewing y Rosegrant, 2006).

La interacción de estas motivaciones establece los que se pueden llamar condicionantes externos de las políticas de promoción de biocombustibles. Además, le otorga al análisis un carácter multidimensional, con efectos en diferentes ejes: político-institucional, agrícola, energético y social, entre otros. Por estos motivos, generalmente en las políticas de apoyo al desarrollo de biocombustibles se combinan distintos instrumentos de política energética, agrícola, comercial y ambiental (Galperín y Pérez Llana, 2009).

En la actualidad, movidos por los factores mencionados y en un contexto de volatilidad de mercados energéticos y de materias primas, los distintos países avanzan cada vez con mayor intensidad en la implementación de políticas públicas para promover la penetración de esta fuente energética. Los resultados alcanzados por cada una de estas políticas dependen en gran medida de sus objetivos y de las características de los países, pero fundamentalmente de los factores político-institucionales existentes en el momento del diseño. Por tales motivos, la hipótesis planteada en este trabajo es que los aspectos institucionales son tan gravitantes como los condicionantes externos en la determinación de las trayectorias sectoriales de los biocombustibles. En otras palabras, se considera que la política de las políticas públicas ${ }^{2}$ tiene

\footnotetext{
${ }^{2}$ El interés por la "política de las políticas públicas" ha sido creciente en la última década. Con el desarrollo de la nueva economía institucional y de la nueva economía política, la literatura sobre el proceso de
}

que estar incorporada en el análisis de la promoción de los biocombustibles.

Al mismo tiempo, el desigual sendero de desarrollo del biodiésel en distintos países a raíz de las políticas energéticas aplicadas, dará lugar a diferentes resultados productivos y distributivos. La estructura institucional implementada para la promoción de los biocombustibles crea incentivos y restricciones que repercuten en las decisiones de inversión de los agentes económicos y, de esta forma, en el nivel de producción. El papel de la estructura institucional es muy importante cuando no existen mercados establecidos y hay incertidumbre con respecto al escenario futuro de los mercados de energía y de las oportunidades económicamente viables. Pero el análisis también debe prestar atención a los efectos no deseados de la política. Sobre todo, en razón de la interacción entre los mercados de biocombustibles y de productos agrícolas, las políticas de promoción del biodiésel tienen un efecto en los precios de los alimentos y en la dinámica de las cadenas de producción de oleaginosas - la materia prima para la producción del biodiésel. Los efectos distributivos son también una cuestión básica del análisis de políticas: examinar los efectos de una política es reconocer quién obtiene qué. Vale decir que la estructura institucional afecta de manera diferente a los costos y beneficios de los participantes, ya que establece derechos o beneficios para algunos agentes que pueden en definitiva representar costos adicionales (o incrementos en los costos) para otros agentes. El establecimiento de diferentes incentivos dará lugar a un grupo ganadores y otro de perdedores que enfrentarán diferentes beneficios o costos a raíz de las políticas.

formulación de políticas enfatiza la importancia de las instituciones en el desempeño comparado de las políticas. Para una aplicación a la realidad de América Latina, véase BID (2006). 


\section{III \\ Condicionantes externos para el desarrollo del biodiésel}

Si bien a nivel global las motivaciones que han llevado al establecimiento de políticas de promoción del biodiésel han sido diversas, a nivel local la Argentina y el Brasil presentan algunas coincidencias y divergencias.

En el caso de la Argentina, el mercado del biodiésel se ha desarrollado mayormente gracias al impulso de la demanda externa, y los principales factores que han impulsado la puesta en marcha de políticas de incentivos han provenido del sector energético, el sector agrícola y los agronegocios. Por su parte, en el Brasil las motivaciones de impulso al biodiésel se encuentran más directamente relacionadas con la promoción social, una cuestión central en la agenda política del presidente Luiz Inácio Lula da Silva ${ }^{3}$, y en forma tangencial, con los aspectos energéticos.

\section{El papel de los mercados energéticos}

Desde mediados del año 2004, la Argentina enfrenta un problema de abastecimiento energético, acentuado recientemente por diferentes factores. En primer lugar, una matriz energética primaria altamente dependiente de los hidrocarburos (87\% de la oferta interna en 2009) y una matriz eléctrica con un $58 \%$ de generación térmica. En segundo lugar, niveles de producción en constante disminución, los que de acuerdo con la información del Instituto Argentino de la Energía (IAE) presentan caídas interanuales del $18 \%$ y del $6 \%$ para el petróleo y el gas natural, respectivamente. En tercer lugar, una reducción en las reservas, manifestada en una constante disminución en sus horizontes de vida y límites en la capacidad de refinación (Recalde, 2011a). La merma de las reservas se puede observar en el gráfico 2 , en que se muestra la evolución de las reservas de gas natural y petróleo (RESGN y RESP, respectivamente) y la evolución del horizonte de reservas - definido como la relación entre las reservas y el nivel de producción- de gas natural (HGN) y petróleo (HPETR), que pone en evidencia los años de vida de las reservas existentes al nivel de

\footnotetext{
${ }^{3}$ Luis Inácio Lula da Silva, perteneciente al partido de los trabajadores, fue presidente de la República del Brasil en el período comprendido entre el 1 de enero de 2003 y el 1 de enero de 2011, siendo sucedido por la candidata de su mismo partido Dilma Rouseff.
}

producción actual. Dicha reducción en el horizonte ha obedecido al agotamiento de los pozos hidrocarburíferos ${ }^{4}$ junto con el descenso en las inversiones en exploración, iniciadas a principios de la década de 1990 luego que se desreglaran y privatizaran las áreas hidrocarburíferas. Esta situación se ha profundizado en los últimos años, como reacción a las distorsiones en los precios a partir de la introducción de los Decretos 310/2002 y 809/2002 y la Resolución 337/2004 del Ministerio de Economía y Producción (Recalde, 2012) 5 .

En este marco, la promoción del biodiésel en la Argentina se relaciona con la relevancia del gasóleo, que representa casi el 50\% del consumo de los combustibles derivados y es el principal combustible utilizado en los sectores de transporte y agropecuario (40\% y $96 \%$, respectivamente, del combustible consumido en el año 2009) ${ }^{6}$. De acuerdo con Chidiak y Stanley (2009) y Recalde (2010), las limitaciones en la oferta de este combustible se deben a que se ha alcanzado el máximo de la capacidad de refinación en el país, lo que se suma al mencionado agotamiento en los pozos. Si bien a partir de 2010-2011 la situación de los combustibles empeoró en igual magnitud para el gasóleo y la nafta, hasta el momento la situación en torno de la importación había sido más grave para el caso del gasóleo ${ }^{7}$ que para el de la nafta, en parte gracias a la "gasificación" del parque automotor.

\footnotetext{
${ }^{4}$ Esta situación podría verse modificada a partir del descubrimiento de grandes yacimientos de petróleo y gas natural no convencional en los años 2010 y 2011. Sin embargo, la magnitud y capacidad económica de explotación de estos no se encuentra evaluada.

${ }^{5}$ Una discusión detallada de la evolución de la producción, las reservas, las inversiones en exploración y sus determinantes se presenta en Recalde (2011b y 2011c).

${ }^{6}$ Información calculada sobre la base de datos de los balances energéticos de la Secretaría de Energía, disponible en: http:energía. mecon.gov.ar

${ }^{7}$ De acuerdo con información de la Secretaría de Energía, la importación de gasóleo en dólares ha sido creciente desde el año 2002, con una disminución en 2009 directamente relacionada con reducciones en la demanda del combustible a raíz de la crisis económica iniciada a mediados de 2007, mientras que la producción en las refinerías locales ha presentado una tendencia interanual decreciente (la variación de la producción de gasóleo ha sido de 7,62\% en 2005/2006; 2,64\% en $2006 / 2007 ;-3,43 \%$ en $2007 / 2008$ y $-3,96 \%$ entre 2008 y 2009 ).
} 


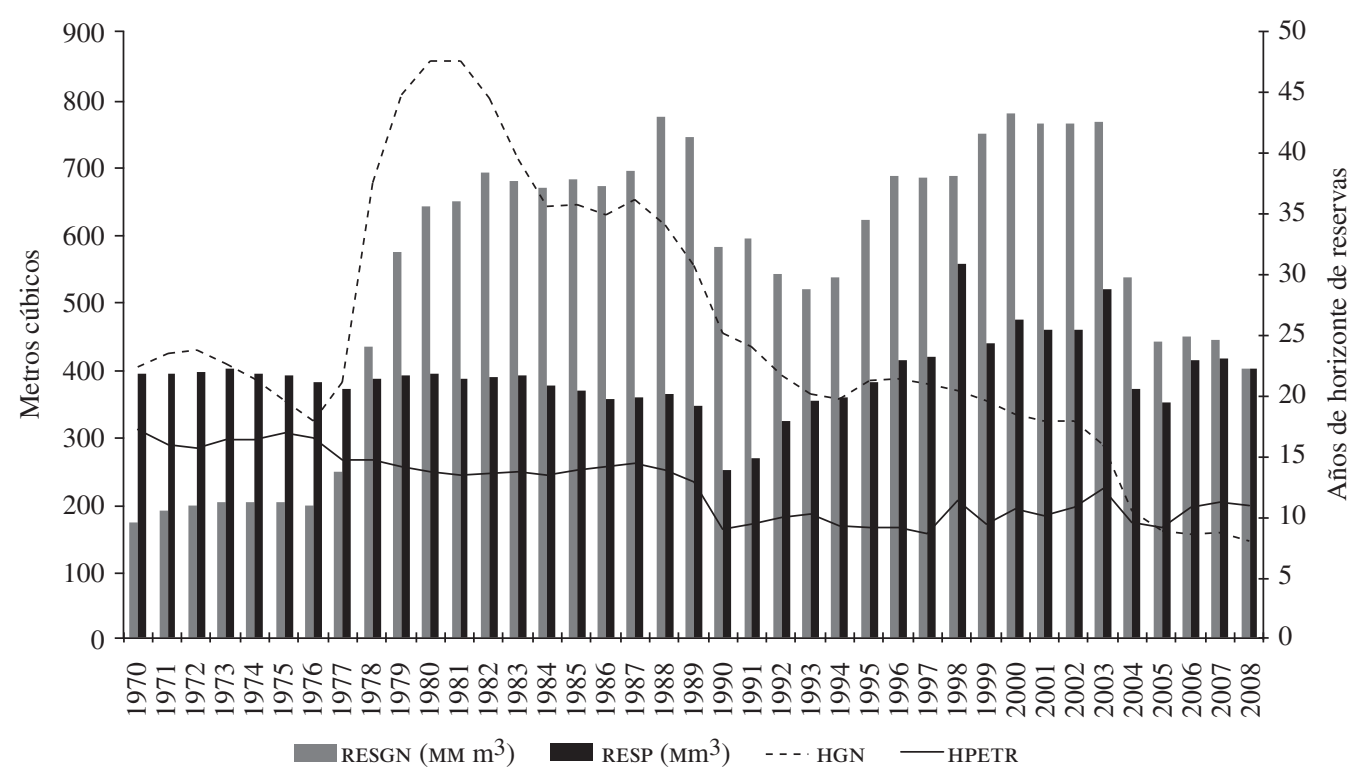

Fuente: M. Recalde, Sistemas energéticos, mercado y Estado. El rol de los recursos naturales energéticos y la política energética en el caso argentino, Madrid, Editorial Académica Española, 2011.

RESGN: las reservas de gas natural $\left(\mathrm{MMm}^{3}\right)$ corresponden a millones de metros cúbicos.

RESP: las reservas de petróleo $\left(\mathrm{Mm}^{3}\right)$ corresponden a miles de metros cúbicos.

HGN: horizonte de reservas de gas natural, relación entre las reservas y el nivel de producción actual de gas natural. HPETR: horizonte de reservas de petróleo, relación entre las reservas y el nivel de producción actual de petróleo.

A diferencia del caso argentino, las motivaciones energéticas se encuentran presentes en el Brasil, pero no tienen un papel significativo. Este país presenta la ventaja de tener experiencia en biocombustibles desde la década de 1970 con el plan de bioetanol de caña de azúcar para la promoción de combustibles renovables. Además, el descubrimiento de grandes yacimientos de petróleo a lo largo de la costa brasileña (llamados las reservas del presal), cambió los parámetros de la seguridad de abastecimiento energético. De acuerdo con las estimaciones realizadas, dicho descubrimiento aportaría reservas de entre 70 y 100 millones de barriles de equivalente en petróleo (BEP), aspecto que ha posicionado al Brasil en el mapa global de la geopolítica del petróleo y ha hecho disminuir sustancialmente los riesgos de escasez.

En el Brasil, las motivaciones en el sector energético no se encuentran ligadas a problemas de abastecimiento general. El país dispone de una matriz eléctrica limpia con alta participación de biocombustibles. Según el balance energético, en el año 2009 el 47,3\% de la oferta interna de energía provenía de fuentes renovables, con un $15,2 \%$ de etanol y derivados de caña, $15,2 \%$ de hidroelectricidad, $10 \%$ de leña y $3,8 \%$ de otras fuentes renovables, incluido el biodiésel. Cabe señalar también que el mantenimiento de una matriz energética limpia es un recurso estratégico para la consolidación de las pretensiones de la diplomacia brasileña. La promoción de los biocombustibles puede ser utilizada para señalar el compromiso del Brasil con la agenda energética mundial y la cuestión del medio ambiente, posiblemente relacionada con los mayores niveles de emisiones de dióxido de carbono $\left(\mathrm{CO}_{2}\right)$ por parte del sector transporte que presenta el Brasil con respecto al caso argentino (véase el gráfico 3).

En el gráfico 4 se pone de relieve la mayor relevancia que tiene el gasóleo en la Argentina respecto de la nafta en relación con el caso brasileño, aspecto que - sumado a la mencionada caída en la producción local de gasóleo- muestra por qué el sector energético ha sido uno de los principales impulsores de la promoción del biodiésel en la Argentina. 
GRÁFICO 3 Argentina y Brasil: evolución de las emisiones de $\mathrm{CO}_{2}$ provenientes del sector transporte

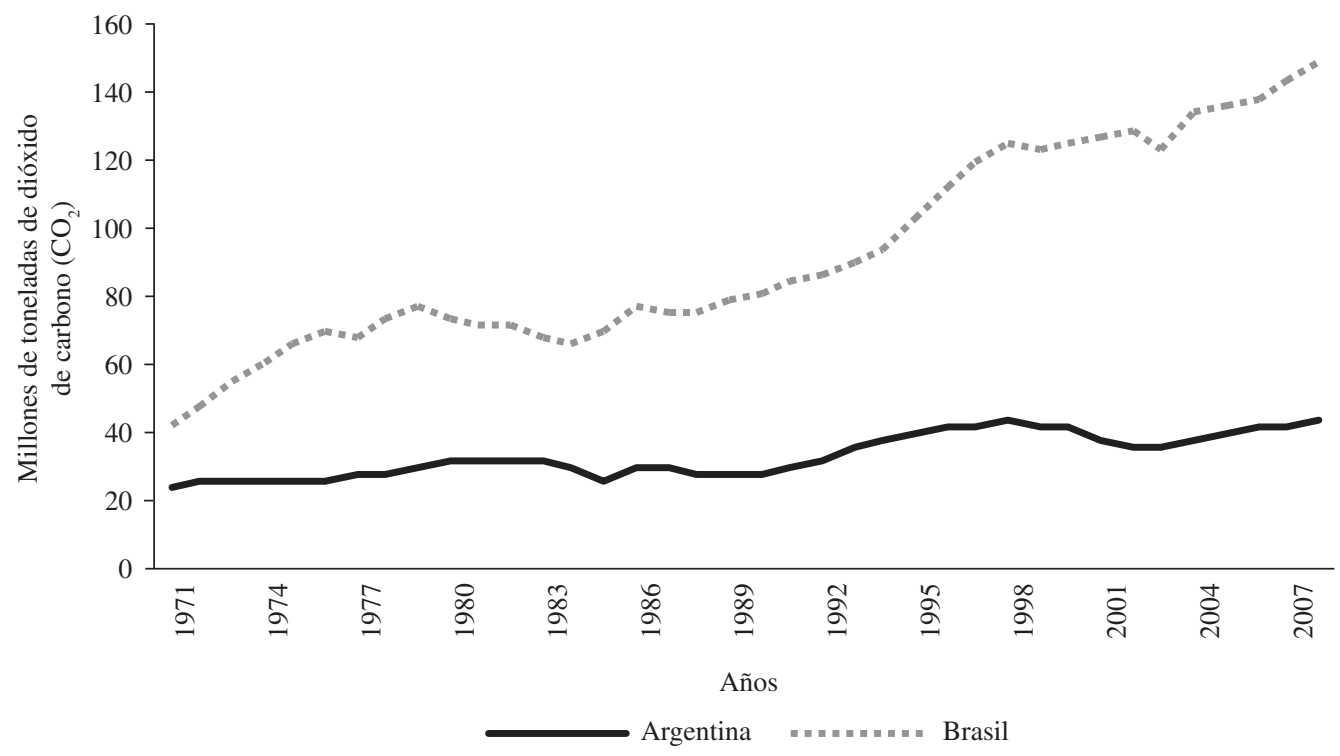

Fuente: elaboración propia sobre la base de datos oficiales de las Naciones Unidas.

GRÁFICO 4

Argentina y Brasil: participación de los distintos combustibles en el sector transporte, 2008

(En porcentajes)

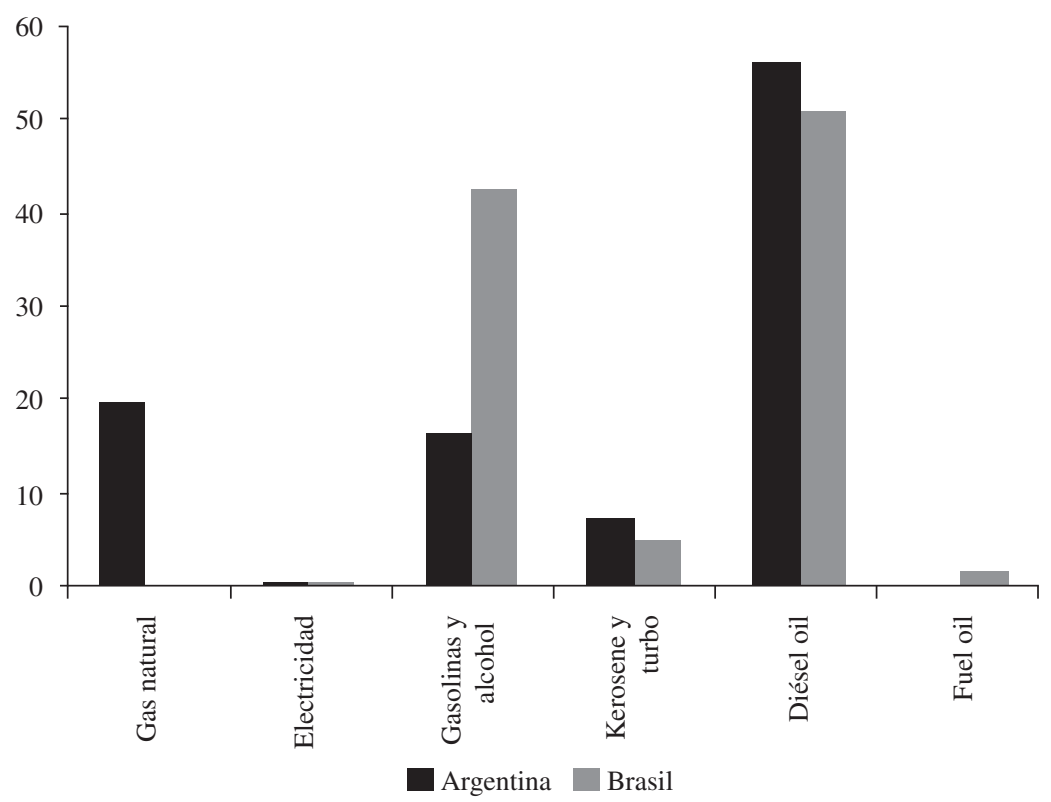

Fuente: elaboración propia sobre la base de datos de Organización Latinoamericana de Energía (OLADE)/Sistema de Información Económica Energética (SIEE). 


\section{El papel impulsor del sector agrícola}

El sector agrícola ha tenido gran relevancia en el impulso a la promoción del biodiésel en el caso argentino, pero no alcanza una dimensión tan importante en el caso brasileño. En la Argentina, la soja representa más del 95\% de la materia prima del biodiésel y es la principal oleaginosa del país, con un crecimiento exponencial en la superficie plantada en los últimos años. Se destina principalmente a la exportación, ya sea en granos o como aceite de soja. En el período 2006-2009, más de la mitad de las exportaciones han ido a China, país que ha sido el principal comprador de aceite de soja. No obstante, desde el año 2009, la decisión estratégica china de procesar el grano en las plantas que comenzaron a levantarse en aquel país incidió de manera directa en la caída de las exportaciones argentinas de aceite de soja $^{8}$. De esta forma, el establecimiento de un mercado local del biodiésel constituye una nueva oportunidad de negocios para las aceiteras y los productores ante la reducción de la demanda externa. Sin embargo, uno de los resultados no esperados del desarrollo del biodiésel en la Argentina es que el mercado externo ${ }^{9}$, más que el interno, ha sido rápidamente su principal impulsor (CADER, 2010).

En tanto que en el Brasil los aspectos agrícolas que impulsaron la formulación de la política de desarrollo del biodiésel son más difusas y se concentran menos en el tema de la soja. La preocupación por la inclusión social de la agricultura familiar fue un motivo importante para la promoción de este biocombustible en el Brasil a partir de la elección del presidente Luiz Inácio Lula da Silva a finales de 2002. Dicha preocupación representó una de las principales razones que llevaron a la institucionalización del Programa Nacional de Producción y Uso de Biodiésel (PNPB) en $2005^{10}$. Existía también la esperanza de que el programa pudiera estimular la

\footnotetext{
${ }^{8}$ En el primer trimestre de 2011, las exportaciones de aceite de soja argentina se redujeron un 39,7\% con respecto al mismo período de 2010 . ${ }^{9}$ En este aspecto se observa que la Argentina ha pasado de ocupar el séptimo lugar en el año 2007 a constituirse en el segundo productor mundial de biodiésel con el 13,1\% del mercado, después de los Estados Unidos de América, que lo lidera con el 14,3\% (CEPAL, 2011). ${ }^{10} \mathrm{De}$ acuerdo con estudios realizados por el Ministerio de Desarrollo Agrario; el Ministerio de Agricultura, Ganadería y Abastecimiento, el Ministerio de Integración Nacional y el Ministerio de las Ciudades, por cada $1 \%$ de sustitución de diésel oil por biodiésel con origen en materias primas de la agricultura familiar se podrían generar 45 mil empleos en el sector rural, con un ingreso aproximado de 3 mil dólares por empleo. Mientras que la agricultura familiar genera un empleo por cada 10 hectáreas (ha), la empresarial crea un empleo por cada 100 ha (Lima, 2005).
}

oferta de aceite de ricino, cuya producción se concentra en el noreste del Brasil, una región pobre y seca, aunque se reconoció la importancia del aceite de soja para abastecer a la cadena de producción del biodiésel, pues la soja es la única oleaginosa que presenta escala de producción suficientemente elevada como para ser considerada competitiva en términos de costos y atender al mercado sin riesgos de desabastecimiento. La creación del mercado del biodiésel representó una oportunidad de negocios relevante, ya que por su intermedio se creó un mercado interno que podría establecer una demanda interna de aceite capaz de brindar estabilidad y seguridad a la cuantiosa oferta de aceite de soja.

\section{Procesos de formulación e instrumentos de promoción}

En la Argentina, los antecedentes directos de la promoción del biodiésel se remontan al año 2001 con el Decreto 1396/2001, que presenta el Plan de Competitividad para el Combustible Biodiésel, donde se declara de interés nacional su producción y se introduce el uso de algunos instrumentos económicos para promover su uso. Sin embargo, el proceso de promoción comienza a consolidarse a partir de 2004, año en que empiezan a evidenciarse los problemas de abastecimiento energético. En dicho año, la Secretaría de Agricultura, Ganadería, Pesca y Alimentos (sagP y A) crea el Programa Nacional de Biocombustibles (Resolución 1156/2004), uno de cuyos principales objetivos fue apoyar y asesorar a sectores rurales para la puesta en marcha de las plantas de biodiésel y bioetanol, como alternativa a la producción local de soja y aceite de soja. En mayo de 2006, se aprueba la Ley 26.093 del "Régimen de Regulación y Promoción para la Producción y Uso Sustentables de Biocombustibles" (reglamentada por el Decreto 109/2007) que otorga el marco legal para la producción de biocombustibles ${ }^{11}$.

Respecto del proceso de formulación, Chidiak y Stanley (2009) resaltan que existieron falencias en el diseño del marco regulatorio, particularmente en la articulación de actores públicos y privados e incluso dentro de distintos subsectores del sector público. La falta de coordinación se relaciona con intereses encontrados de los distintos sectores. En lo que atañe al sector

\footnotetext{
${ }^{11}$ El proyecto de ley fue presentado ante el Senado de la Nación, el 6 de julio de 2004. Entre algunos de los aspectos presentes en el proyecto de ley, que luego fueron eliminados, se destaca que los beneficios podían ser alcanzados por cualquier empresa, incluso empresas petroleras, mientras que en la ley se menciona que los incentivos son preferentemente para pequeñas y medianas empresas (pymes).
} 
público, esto se observa en las opiniones diferentes del Ministerio de Economía y Finanzas Públicas (ME), el Instituto Nacional de Tecnología Industrial (INTI) y el Instituto Nacional de Tecnología Agropecuaria (INTA) o el Ministerio de Agricultura, Ganadería y Pesca (MAG y P). Con respecto al sector privado se observa la presión de sectores ligados a los dos primeros eslabones de la cadena del biodiésel, entre los que se encuentran la Asociación Argentina de Biocombustibles e Hidrógeno (AAHB), la Federación Agraria Argentina (FAA) y la Cámara Argentina de Biocombustibles (CARBIO), y de la opinión pública vinculada al sector.

Una de las controversias que surgieron se relacionó con el tipo de incentivos económicos establecidos y su repercusión potencial en las cuentas nacionales. Los intereses encontrados eran sobre todo los ligados al sector del agro y los del $\mathrm{ME}^{12}$. El argumento por parte de este ministerio se refería a la recaudación fiscal. Los impuestos a los combustibles representaban en el año 2004 el 5,5\% de los recursos tributarios totales, las retenciones a las exportaciones de soja el $12 \%$ de la recaudación, y el IVA aportaba el 30\% de los recursos.

Otra de las modificaciones al proyecto de ley fue la incorporación de consejos federales provinciales y entidades privadas en la Comisión Nacional Asesora para la Promoción de la Producción y Uso Sustentables de los Biocombustibles, así como el otorgamiento a este ente de la facultad para establecer precios de referencia. La autoridad de aplicación recae en la Secretaría de Energía, dependiente del Ministerio de Planificación Federal, Inversión Pública y Servicio, que será apoyada por la Comisión Nacional Asesora antes mencionada, creada mediante el artículo 3 de la Ley 26.09313. Las especificaciones en torno de la calidad que debe cumplir el B100 ${ }^{14}$ para ser

\footnotetext{
${ }^{12}$ Mientras que el proyecto de ley contemplaba la exención al impuesto al gasóleo $(20,2 \%)$ y de la tasa de infraestructura hídrica $(\$ 0,05$ por litro de nafta), la contraoferta del ministerio era la devolución del débito fiscal de las ventas de biocombustibles, la amortización acelerada de ganancias para las plantas de elaboración, y exenciones de aranceles a la importación de insumos y del impuesto a la ganancia mínima presunta.

${ }^{13}$ Dicha Comisión está integrada por un representante de la Secretaría de Energía; la Secretaría de Agricultura, Ganadería, Pesca y Alimentos; la Secretaría de Ambiente y Desarrollo Sustentable (SA y DS); la Secretaría de Hacienda; la Secretaría de Política Económica; la Secretaría de Industria, Comercio y de la Pequeña y Mediana Empresa; y el Ministerio de Ciencia, Tecnología e Innovación Productiva y la Administración Federal de Ingresos Públicos (AFIP).

${ }^{14} \mathrm{El}$ término biodiésel alude al combustible puro - denominado B100 - que ha sido designado como combustible alternativo por los Departamentos de Energía y de Transporte de los Estados Unidos de América. El B100 puede usarse en estado puro, pero se emplea con mayor frecuencia como aditivo para el combustible diésel convencional.
}

mezclado con un porcentaje de gasóleo son establecidas en el año 2010 por medio de la Resolución 6/2010 y su posterior modificación mediante la Resolución 828/2010. En julio de 2010 con la Resolución 554/2010 se eleva al $7 \%$ el porcentaje de corte obligatorio para el gasóleo inicialmente establecido en 5\%. Esta ampliación del cupo parece reflejar una voluntad tendiente a aumentar el corte obligatorio hasta el $10 \%$, permitiendo reducir las crecientes importaciones de gasóleo y diésel oil. Con respecto a los productores que forman parte de la cadena para el abastecimiento interno (alcanzados por los incentivos de la ley), las empresas elaboradoras se comprometen a suministrar una cantidad de biodiésel suficiente para cumplir con el corte del $5 \%$ y a ponerla a disposición de las empresas mezcladoras.

A diferencia de la Argentina, el Brasil es un país que cuenta con una vasta experiencia en la promoción de las energías renovables, especialmente en lo referido a los biocombustibles. En los años setenta, en respuesta a la crisis internacional del petróleo y a la crisis local de la divisa, y con el fin de reducir la dependencia del petróleo, se puso en marcha en el Brasil una política de incentivo a las energías renovables. En este sentido, se destaca el Programa Nacional del Alcohol (Pró-Álcool), destinado a incentivar la producción de etanol de caña de azúcar. Sin embargo, la incorporación del biodiésel a la agenda de la política energética se produce recién desde fines de los años noventa o inicios de la década de 2000.

En una primera etapa de elaboración, el gobierno federal organizó comisiones interdisciplinarias entre los ministerios, universidades y centros de investigación ${ }^{15}$. En esta fase, las motivaciones se relacionaban con las cuestiones energéticas y ambientales, y con los intereses agrícolas del sector empresarial ${ }^{16}$. Sin embargo, con la llegada al gobierno de Luiz Inácio Lula da Silva hacia finales del año 2002, se reformuló completamente el Programa Nacional para la Producción de Biodiésel (PROBIODIÉSEL), incorporándose las metas de inclusión social en concordancia con los pilares fundamentales del nuevo gobierno.

\footnotetext{
15 Uno de los marcos de esta trayectoria fue el Programa Brasileiro de Biocombustíveis (PROBIODIÉSEL), lanzado en el año 2002 y coordinado por el Ministerio de Ciencia y Tecnología (MCT). El diseño del programa contó con la participación efectiva de más de 200 especialistas y organizaciones de la Red Brasileña de Tecnología de Biodiésel.

${ }^{16}$ Los instrumentos de implementación del programa eran: i) la disminución de la dependencia de los derivados del petróleo; ii) la creación de nuevos mercados para las oleaginosas, particularmente la soja; iii) el crecimiento de la demanda global de combustibles alternativos, y iv) educción de las emisiones de gas de carbono.
} 
En el año 2003 se instituye un Grupo de Trabajo Interministerial (GTI) y la gestión de la política del biodiésel pasó del Ministerio de Ciencia y Tecnología (мСт) a la Casa Civil ${ }^{17}$. Luego de la publicación del informe del GTI, el biodiésel fue introducido en la matriz energética brasileña mediante el lanzamiento en diciembre de 2004 del Programa Nacional de Producción y Uso de Biodiésel (PNPB).

Los tres pilares fundamentales del PNPB son la inclusión social mediante la agricultura familiar, la sustentabilidad ambiental y la viabilidad económica. En este programa, el biodiésel fue definido como un combustible de uso forzoso, con un corte obligatorio al diésel en porcentajes que variarán del $2 \%$ entre 2008 y 2012 al 5\% a partir de 2012. La implementación de la política del biodiésel implicó cambios institucionales, como por ejemplo, la Agencia Nacional del Petróleo pasó a llamarse Agencia Nacional de Petróleo, Gas Natural y Biocombustibles (ANP).

La consolidación del mercado del biodiésel se garantiza mediante la realización de subastas públicas promovidas por la ANP, disputadas en condiciones especiales por aquellas empresas que cuentan con un sello de combustible social (SCS), y una certificación concedida a las industrias que utilizan productos provenientes de la agricultura familiar. El objetivo de las subastas es garantizar el cumplimiento de las metas del PNPB. Dentro de este programa, Petrobras ha jugado un papel fundamental, puesto que se constituye como el único comprador y principal responsable de la mezcla estipulado en la legislación, además de la Refinería Alberto Pasqualini (REFAP), también controlada por Petrobras.

En el PNPB se combinan diferentes instrumentos de promoción, como por ejemplo, la institucionalización de subastas de compra (garantía de precios), la definición de un régimen tributario diferenciado (para garantizar la inclusión social) y la determinación de metas de corte obligatorias (a objeto de garantizar la existencia de un mercado).

\section{- Instrumentos utilizados}

Tal como ya se mencionara, actualmente en muchos países del mundo se desarrollan políticas para promover la producción de biocombustibles. Existe una variedad de instrumentos de promoción, que pueden ser utilizados en forma aislada o combinada, según los objetivos de política y las características del país en cuestión. La elección entre uno u otro elemento dependerá de un conjunto de

\footnotetext{
17 Jefe de Gabinete de la Presidencia de la República.
}

factores que deben ser evaluados. Entre algunos de los principales instrumentos que comprenden incentivos financieros se encuentran las reducciones fiscales (a la inversión, a los créditos, esquemas de amortización diferencial del capital) y los sistemas de financiamiento (establecimiento de mecanismos claros, reducción del riesgo implícito de la inversión, determinación de garantías para mejorar el acceso al financiamiento bancario, préstamos a bajo interés). En el caso de la Argentina y el Brasil, estos instrumentos se combinan dando lugar a un esquema de promoción característico en cada caso. En los cuadros 1 y 2 se muestran los instrumentos de promoción vigentes en ambos países.

En la Argentina y en el Brasil se combinan instrumentos de política tanto de cantidad como de precios. En el primer grupo se encuadra el establecimiento de un corte obligatorio al gasóleo. Este instrumento permite a las empresas asegurar un cupo para sus producciones en el mercado interno. Entre los instrumentos de precios se halla una combinación de beneficios impositivos o fiscales.

En la Argentina, todos los beneficios promocionales establecidos por la Ley 26.096 tienen un alcance establecido en el artículo 13 para proyectos de industrias radicadas en el país, que se dediquen exclusivamente a la producción de biocombustibles destinados al mercado interno; es decir, empresas con mayoría de capital estatal o de productores agropecuarios (quienes deben justificar como mínimo el 50\% de sus activos afectados en la Argentina) con habilitación exclusiva para producción de biocombustibles. Además, junto con las políticas de precios y cantidad establecidas en la ley y sus decretos reglamentarios también existen regulaciones de la calidad que deben cumplir los biocombustibles en general y el biodiésel en particular; al respecto las disposiciones establecen claramente que las empresas deben contar en sus plantas con el instrumental necesario para medir dichas normas de calidad.

No obstante el establecimiento de estos instrumentos de promoción, muchos autores resaltan que uno de los principales factores que han impulsado recientemente la producción de biodiésel ha sido el efecto de las diferentes alícuotas aplicadas a la exportación del grano de soja, el aceite y el biodiésel. Este impuesto, conocido internamente como retenciones a las exportaciones, ha sido aproximadamente del $35 \%$ para el grano, $32 \%$ para el aceite y solo del $20 \%$ para el biocombustible, constituyéndose entonces en uno de los factores clave de impulso a la producción.

Finalmente, con miras a una utilización alternativa del biodiésel, se puede mencionar la implementación 


\begin{tabular}{|c|c|c|c|c|c|c|}
\hline \multirow[b]{3}{*}{$\begin{array}{l}\text { Instrumento } \\
\text { legal }\end{array}$} & \multicolumn{6}{|c|}{ Tipo de instrumento } \\
\hline & \multicolumn{2}{|l|}{$\begin{array}{l}\text { Requerimientos } \\
\text { cuantitativos }\end{array}$} & \multicolumn{3}{|c|}{ Incentivos financieros } & \multirow[b]{2}{*}{$\begin{array}{l}\text { Impuesto a la } \\
\text { transferencia o } \\
\text { importación de } \\
\text { gasóleo }\end{array}$} \\
\hline & Cuota & IVA & $\begin{array}{l}\text { Impuesto a } \\
\text { las ganancias }\end{array}$ & $\begin{array}{l}\text { Impuesto a los } \\
\text { combustibles } \\
\text { líquidos }\end{array}$ & $\begin{array}{l}\text { Tasa de } \\
\text { infraestructura } \\
\text { hídrica }\end{array}$ & \\
\hline Ley 26.096 & $5 \%$ & $\begin{array}{l}\text { Devolución del } \\
\text { porcentaje de bienes } \\
\text { de capital y/u obras } \\
\text { de infraestructura }\end{array}$ & $\begin{array}{l}\text { Amortización } \\
\text { acelerada }\end{array}$ & $\begin{array}{l}\text { Eximición para } \\
\text { el porcentaje de } \\
\text { biocombustible } \\
\text { en la mezcla }\end{array}$ & $\begin{array}{l}\text { Eximición para } \\
\text { el porcentaje de } \\
\text { biocombustible } \\
\text { en la mezcla }\end{array}$ & $\begin{array}{l}\text { Eximición para } \\
\text { el porcentaje de } \\
\text { biocombustible } \\
\text { en la mezcla }\end{array}$ \\
\hline Resolución 554/2010 & $7 \%$ & & & & & \\
\hline
\end{tabular}

\section{Requerimientos cualitativos}

Resolución No 6/2010 y $N^{\circ} 828 / 2010$ (ambas del año 2010)

GENREN
Especificaciones en torno de la calidad que debe cumplir el biocombustible para ser mezclado con x porcentaje de gasóleo.

Llamado a licitación pública para cubrir 150MW de generación térmica con biocombustibles destinada a insertarse en el mercado eléctrico mayorista.

Se ofrece obligación de compra por contrato por 15 años y precio preestablecido en la licitación.

Fuente: elaboración propia sobre la base de la Ley 26.096 y resoluciones reglamentarias.

GENREN: Programa de licitación para la generación eléctrica a partir de energías renovables.

CUADRO 2

Brasil: instrumentos de precios en la promoción del biodiésel

\begin{tabular}{|c|c|c|c|c|}
\hline Tributos federales & $\begin{array}{l}\text { Agricultura familiar, norte, } \\
\text { nordeste y semiárido }\end{array}$ & $\begin{array}{l}\text { Agricultura familiar de } \\
\text { forma general }\end{array}$ & $\begin{array}{l}\text { Regla general (otras } \\
\text { formas de agricultura) }\end{array}$ & $\begin{array}{l}\text { Diésel } \\
\text { mineral }\end{array}$ \\
\hline $\mathrm{IPI}^{\mathrm{a}}$ & - & - & - & - \\
\hline $\mathrm{CIDE}^{\mathrm{b}}$ & Inexistente & Inexistente & Inexistente & $\mathrm{R} \$ 0,07$ \\
\hline PIS/PASEP y COFINS ${ }^{\mathrm{c}}$ & Reducción de hasta $100 \%$ & Reducción de hasta $68 \%$ & $\begin{array}{l}\mathrm{R} \$ 0,22 \text { (siempre inferior } \\
\mathrm{o} \text { igual al diésel mineral) }\end{array}$ & $\mathrm{R} \$ 0,148$ \\
\hline Total (por litro) & $R \$ 0,00$ & $R \$ 0,07$ & $R \$ 0,218$ & $R \$ 0,218$ \\
\hline
\end{tabular}

Fuente: elaboración propia sobre la base de Decreto 5.297 (6/12/2004), Decreto 5.298 (6/12/2004) e instrucción normativa No 1 del Ministério de Desarrollo Agragrio, 19 de febrero de 2009.

a Impuesto sobre productos industrializados.

b Contribución de dominio económico.

c Contribuciones sociales.

por parte de la Secretaría de Energía en el año 2009 del Programa de licitación para la Generación Eléctrica a partir de Energías Renovables (GENREN), que preveía una cuota de $150 \mathrm{MW}$ para proyectos de generación con biocombustibles. De acuerdo con la información oficial provista por Energía Argentina S.A. (ENARSA), los precios a los que fueron asignados los proyectos térmicos con biocombustibles seleccionados van desde 258 hasta 297 US\$/MWh.
Tal como se mencionara anteriormente, la innovación del programa brasileño es la puesta en marcha de licitaciones con precios diferenciales entre los proyectos que cumplan las metas de promoción de la agricultura familiar y aquellos que no lo hagan. Así, la inclusión social fue incentivada por medio del diseño de un modelo tributario que favorece la inclusión de la agricultura familiar y el desempeño de las regiones semiáridas y del norte, que tradicionalmente presentan 
indicadores de desarrollo humano inferiores a los de las demás regiones del país. Para esto se diseñó un sello que permite diferenciar las categorías de agricultores, regiones y materias primas y hacer una combinación de estos factores. El sello combustible social es un certificado concedido por el Ministerio de Desarrollo Agrario (MDA) a aquellas empresas productoras que compran en la agricultura familiar ${ }^{18}$. Entre algunos de los incentivos provistos a quienes detenten el sello se encuentra el establecimiento de líneas de financiamiento específicas del Banco Nacional de Desarrollo Económico y Social (BNDES) ${ }^{19}$ y el direccionamiento de algunas de

${ }^{18}$ El sello fue reformulado en febrero de 2009 como resultado de debates entre representantes de la agricultura familiar y de las industrias procesadoras de aceite y productoras de biodiésel. De esta manera, los porcentajes para la adquisición de la materia prima de la agricultura familiar fueron modificados, pasando a ser del $15 \%$ para las regiones del norte y centro-oeste y del $30 \%$ para el sur, sureste, nordeste y semiárido. ${ }^{19}$ A partir de 2010, pasó a llamarse Banco de Desarrollo del Brasil (BNDES). las líneas del Programa Nacional de Fortalecimiento de la Agricultura Familiar (PRONAF) para aquellos agricultores que planten oleaginosas.

El porcentaje de corte establecido constituye otro de los principales instrumentos de promoción. Las posiciones encontradas en este debate surgen de quienes quieren un crecimiento rápido del mercado -el segmento agrícola e industrial y aquellos que defienden un crecimiento moderado, con un ritmo más acorde con la inclusión de los pequeños agricultores. Mientras que el nivel de corte inicial fue establecido en un 2\%, en julio de 2008 la proporción se incrementó al 3\%, en enero de 2009 al $4 \%$ y en abril de 2010 se estableció un $5 \% 20$.

${ }^{20}$ Desde el año 2010 la ANP se encuentra discutiendo el establecimiento de la obligatoriedad del uso de biodiésel también en el transporte marítimo. Además, los grupos en favor de la ampliación del corte defienden una obligatoriedad del $10 \%$.

\section{IV}

\section{Situación actual y potenciales efectos de las políticas de promoción}

En el cuadro 3 se presentan en forma comparativa los condicionantes externos, las características principales de la formulación de las políticas y algunos de los principales resultados alcanzados. A continuación se analiza la situación actual y las potenciales repercusiones en cada uno de los sectores afectados por la elaboración de estas políticas. Es importante aclarar que dado el escaso horizonte temporal en la evaluación de las políticas, algunos de los resultados que se observan pueden no ser el efecto directo de la puesta en marcha de las políticas, sino responder a la acción de factores externos. Este es sobre todo el caso de la Argentina, donde el mayor impulso a los biocombustibles ha venido de la mano de la demanda externa.

\section{Situación actual del sector energético}

Como ya se dijo, en la Argentina el peso de las importaciones de combustibles en las importaciones totales pasó del 4,84\% en 2004 al 7,78\% en 2010. Tal como se observa en el gráfico 5, a partir de 2005 el consumo de gasóleo y diésel oil se separa de la producción local implicando necesariamente un incremento de la importación de ambos combustibles. Cabe destacar que dado el breve tiempo transcurrido desde la puesta en marcha de la política, los resultados aún no se encuentran disponibles en estadísticas oficiales. No obstante, de acuerdo con las estimaciones del Ministro de Planificación, ante el aumento del corte obligatorio de gasóleo estipulado en un $7 \%$, el consumo anual de biodiésel en el mercado interno pasará de 750.000 toneladas a 1,05 millones de ton/ año, que es prácticamente el mismo volumen de gasóleo que importa la Argentina anualmente. Si este fuera el caso, los resultados obtenidos en torno de los objetivos energéticos podrían llegar a ser satisfactorios.

De manera similar, en el Brasil el diésel constituye un rubro gravitante en las importaciones, pese a que en este caso, a diferencia del argentino, se observa un crecimiento en la producción del combustible. En el año 2010, el Brasil importó cerca de 9.000 millones de litros del combustible, a raíz principalmente del crecimiento del consumo interno. Tal como se observa en el gráfico 6, el crecimiento de la producción de 


\section{Argentina y Brasil: situación comparativa}

\begin{tabular}{|c|c|c|c|}
\hline & $\begin{array}{l}\text { Condicionantes externos } \\
\text { (impulsores) }\end{array}$ & $\begin{array}{l}\text { Formulación de políticas } \\
\text { (actores, reglas, escenarios) }\end{array}$ & $\begin{array}{c}\text { Resultados } \\
\text { (distributivos, asignativos) }\end{array}$ \\
\hline Argentina & $\begin{array}{l}\text { - Aumentos en el déficit de la balanza } \\
\text { energética: incrementos en las impor- } \\
\text { taciones de diésel oil por restricciones } \\
\text { en la capacidad de oferta. } \\
\text { - Caída de la demanda de China. } \\
\text { - Presiones por parte de los principales } \\
\text { actores de la cadena. } \\
\text { - Papel del mercado externo del bio- } \\
\text { diésel en el impulso a la industria } \\
\text { supera al impulso local. }\end{array}$ & $\begin{array}{l}\text { - Principales grupos de presión involucrados: } \\
\text { Estado por intermedio de Secretaría de } \\
\text { Energía y Finanzas Públicas; Ministerio de } \\
\text { Economía; Instituto Nacional de Tecnología } \\
\text { Agropecuaria (INTA); Asociación Argentina } \\
\text { de Biocombustibles e Hidrógeno (AAHB); } \\
\text { Federación Agraria Argentina (FAA) y Cámara } \\
\text { Argentina de Biocombustibles (CARBIO) } \\
\text { - Instrumentos específicos: corte obligatorio } \\
\text { (7\%), exenciones impositivas varias; subastas } \\
\text { por medio del programa GENREN }\end{array}$ & $\begin{array}{l}\text { - Muy alta capacidad de produción. } \\
\text { - Apropiación de las ganancias por } \\
\text { parte de los principales agentes en la } \\
\text { cadena de la soja: grandes aceiteras. } \\
\text { - Integración de la cadena sojera. } \\
\text { - Concentración de la capacidad de } \\
\text { producción. } \\
\text { - Efectos en la concentración de la } \\
\text { tierra para producción de soja. }\end{array}$ \\
\hline Brasil & $\begin{array}{l}\text { - Agenda presidencial del Presidente } \\
\text { Lula (inclusión social) y poder pre- } \\
\text { sidencial (PNPB) Agenda ambiental. } \\
\text { - Precios del petróleo y del diésel } \\
\text { (importado en el Brasil). } \\
\text { - Antecedente exitoso en las políticas } \\
\text { de biocombustibles (pathdependent) }\end{array}$ & $\begin{array}{l}\text { - Principales grupos de presión involucrados: } \\
\text { Estado por intermedio de Petrobras; asocia- } \\
\text { ción de productores de biodiésel; industria } \\
\text { automotriz; industria de los combustibles; } \\
\text { instituciones de la agricultura familiar (mi- } \\
\text { nisterio, sindicatos, movimientos sociales). } \\
\text { - Instrumentos específicos: sello social, subastas } \\
\text { públicas ANP, corte obligatorio 5\% (2012), re- } \\
\text { ducción de los impuestos PIS/PASEP y COFINS } \\
\text { - Distribución de los derechos de decisión } \\
\text { (Ministério de: Minas e Energia, ANP) }\end{array}$ & $\begin{array}{l}\text { - Alta capacidad de producción, } \\
\text { aunque inferior a la capacidad } \\
\text { argentina. } \\
\text { - Apropriación de las ganancias por } \\
\text { parte de la cadena de la soja. } \\
\text { - Beneficios para las regiones produc- } \\
\text { toras de soja (sur y centro-oeste). } \\
\text { - Alta presencia de Petrobras para el } \\
\text { cumplimiento de las metas sociales. }\end{array}$ \\
\hline
\end{tabular}

Fuente: elaboración propia.

GENREN: Programa de licitación de generación eléctrica a partir de energías renovables.

a Contribuciones sociales.

GRÁFICO 5

Argentina: consumo, producción e importación de diésel oil y gasóleo, 2000-2009 (En miles de metros cúbicos)

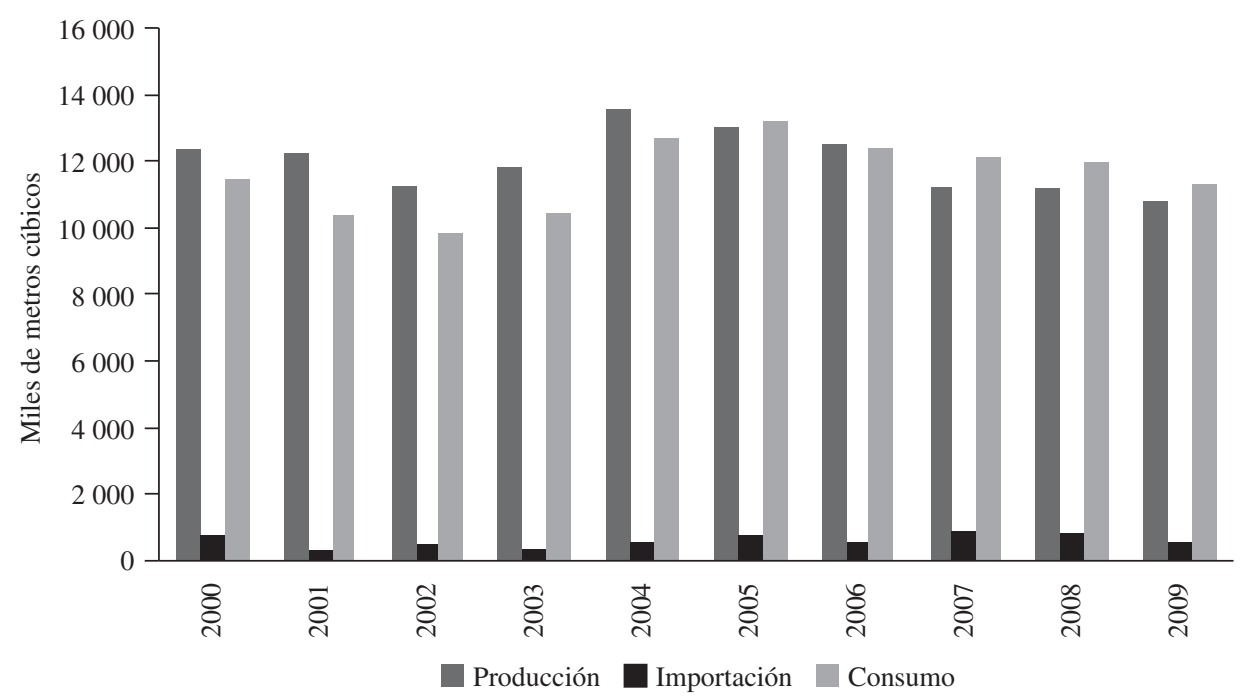

Fuente: elaboración propia sobre la base de balances de la Secretaría de Energía y Finanzas Públicas. 
diésel y la puesta en marcha del corte obligatorio han dado como resultado un estancamiento de las importaciones. De acuerdo con Senatore y otros (2010), entre 2005 y 2010 el Brasil ha logrado ahorrar 2.840 millones de dólares en las importaciones de diésel, gracias al aumento de la producción interna y a la sustitución de parte del diésel por biodiésel.

\section{Situación actual del sector agrícola y la cadena productiva del biodiésel}

En la Argentina, la capacidad de elaboración del biodiésel se incrementó exponencialmente entre 2006 y 2010, pasando de 130.000 a 2,5 millones de toneladas, respectivamente. Sin embargo, a diferencia del caso brasileño, este crecimiento en la capacidad instalada no se relaciona exclusivamente con el impulso a partir de la regulación de la actividad, puesto que el $51 \%$ se destina a la exportación y el $43 \%$ al mercado interno. Una de las características del sector es la gran capacidad de producción promedio de sus plantas, que se ubica en cerca de 110.000 toneladas. En especial, se destacan al menos cinco grandes aceiteras cuya capacidad de producción supera las 250.000 toneladas, y que destinan más del $75 \%$ a la exportación. Este tipo de producciones no se ven favorecidas por los impulsos de la ley, puesto que esta solo atañe a la producción con destino interno. Así, la legislación no ha tenido un efecto significativo en el desarrollo del mercado, excepto en las plantas elaboradoras pequeñas, $6 \%$ de la capacidad instalada y que destinan el $100 \%$ de su producción al mercado interno.

La producción de biodiésel es una oportunidad para los productores de soja de ampliar el canal de comercialización y las ganancias obtenidas a lo largo de la cadena, motivo por el cual muchos de ellos participan en el eslabón de elaboración. Al mismo tiempo, la repercusión del aumento de la producción de biodiésel en la producción de soja se puede observar en el incremento en la producción de la oleaginosa que representa el $88 \%$ de la superficie cosechada en 2008-2009, tal como se observa en gráfico 7. Sin embargo, la evolución de la soja se ha encontrado atada a la evolución del mercado externo, en el que la exportación de harinas ocupa el mayor porcentaje. De acuerdo con información del

GRÁFICO 6

Brasil: consumo, producción e importación de diésel, 2004- 2009

(En miles de metros cúbicos)

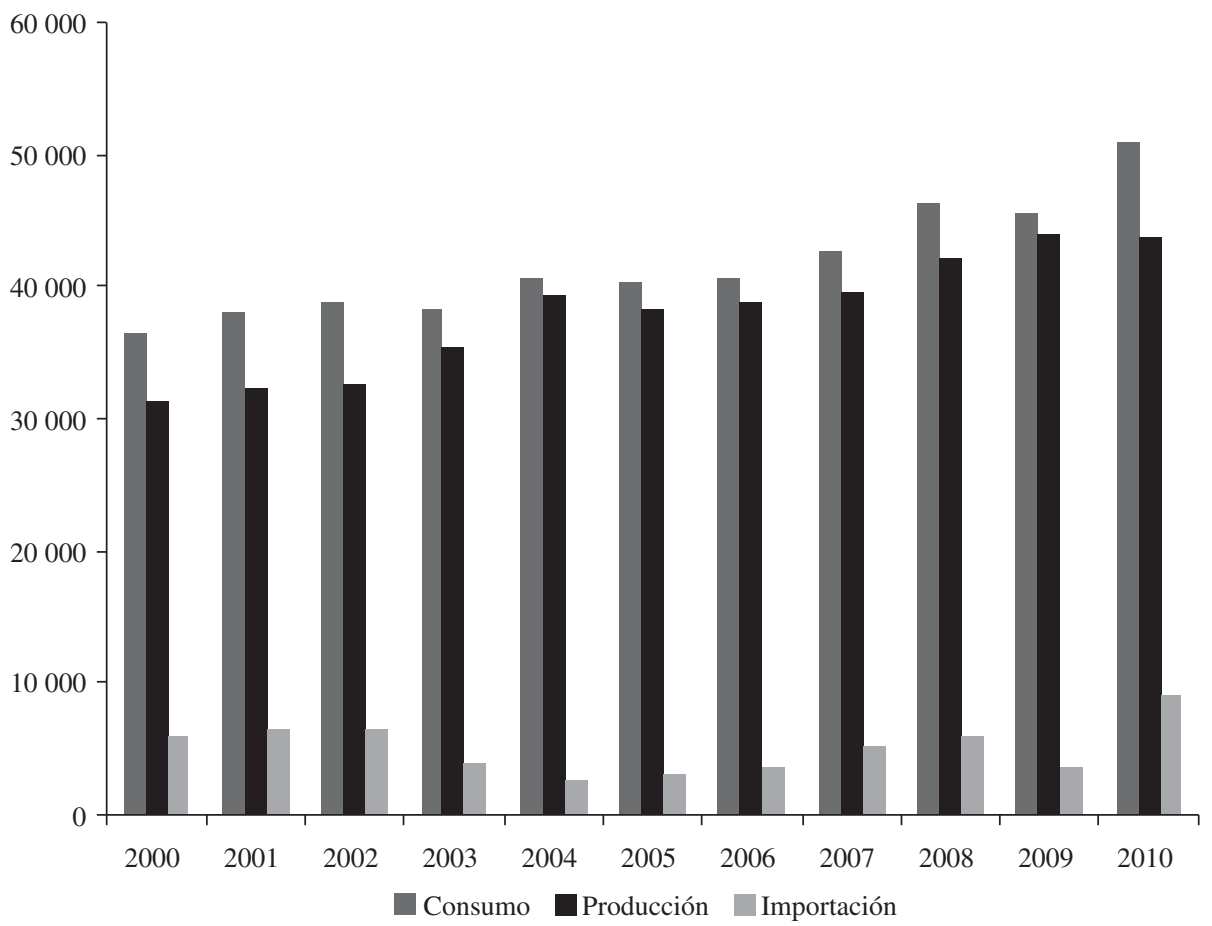

Fuente: Ministerio de Minas y Energía, Balanço energético nacional 2010, Brasilia, 2010. 


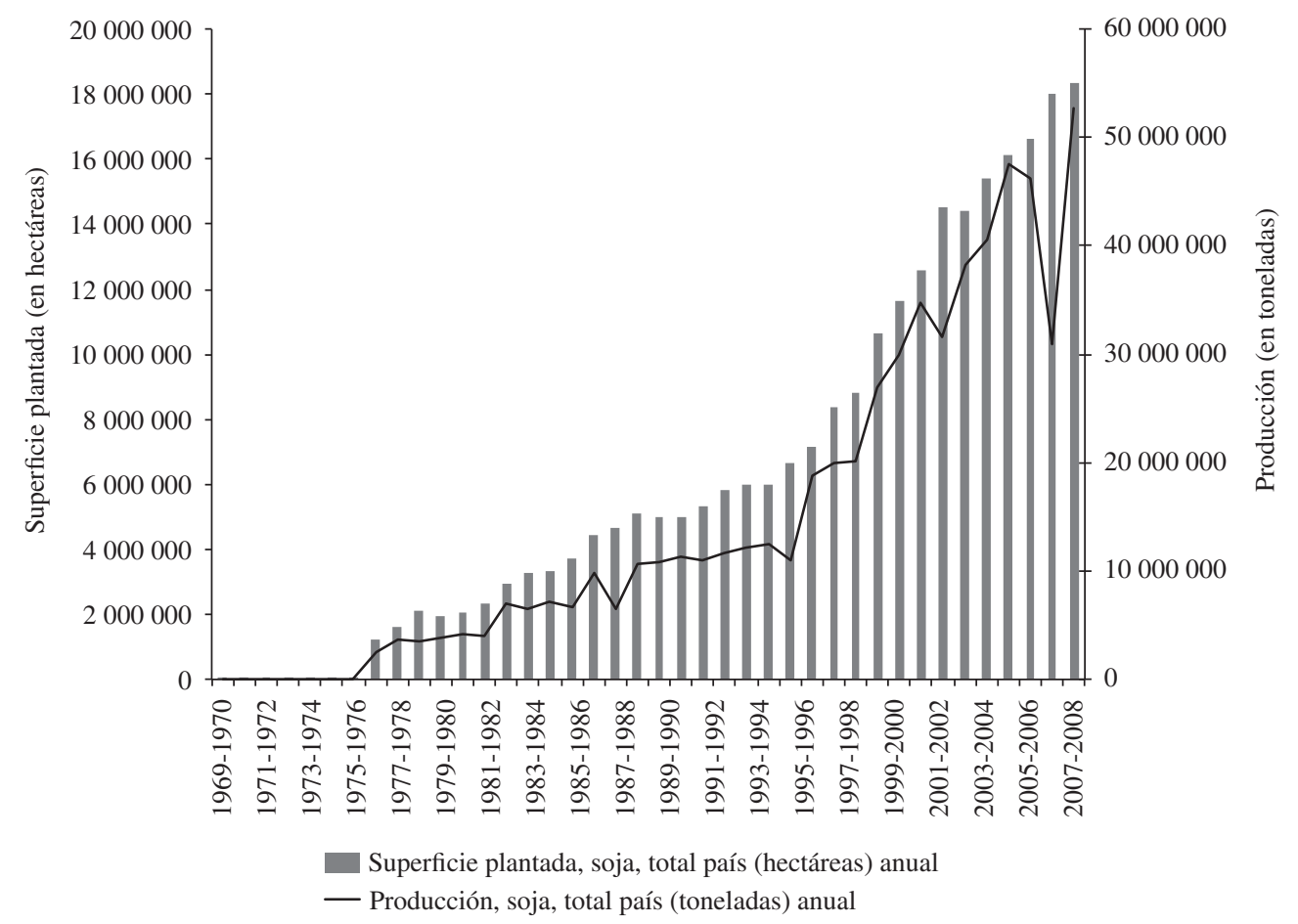

Fuente: elaboración propia sobre la base de información del Ministerio de Agricultura Ganadería y Pesca (MAG y P).

Instituto Nacional de Estadística y Censos (INDEC) ${ }^{21}$, entre 2007 y 2009 las exportaciones del complejo sojero han representado en promedio el $24 \%$ de las exportaciones totales, con valores cercanos a los 15.000 millones de dólares.

Por el contrario, en el Brasil la formulación del PNPB impulsó a la industria local del biodiésel casi en forma instantánea. En un corto período de cinco años, a raíz del programa se formó un parque industrial capaz de producir más de 5.000 millones de litros de biodiésel por año. Dado que con el corte obligatorio al $5 \%$ del combustible la demanda estimada es de 2.500 millones de litros, no parecen existir riesgos de desabastecimiento en el corto plazo y las industrias se encuentran operando con capacidad ociosa. A diferencia del caso argentino, la casi totalidad de la producción se encuentra destinada

\footnotetext{
${ }^{21}$ Disponible en: www.indec.gov.ar
}

al mercado interno y raramente las empresas exportan parte de su producción ${ }^{22}$.

Dado el crecimiento del mercado del biodiésel, los productores están buscando una estrategia de integración que les permita tener mayor control sobre la cadena a través del dominio de la principal materia prima, la soja, y en algunos casos del sebo bobino. En este proceso se observa la entrada de multinacionales tales como la ADM (Archer Daniels Midland Company) o Cargill, y la ampliación del tamaño medio de las plantas, que han pasado de 64.000 litros anuales en 2008 a 75.000 por año en mayo de 2010. No obstante, se puede apreciar que el tamaño medio de las plantas brasileñas es inferior al de las argentinas. En el mismo período se aprecia también un incremento en el número y capacidad de las plantas, aumentando de seis a nueve las plantas con capacidad

${ }^{22}$ La industria del biodiésel en la Argentina se encuentra relativamente concentrada. Cerca del $60 \%$ de la capacidad de producción corresponde a 10 empresas. 
mayor de 150.000 litros y de una a tres las que tienen una capacidad que sobrepasa los 300.000 litros.

\section{Aspectos sociales e incidencia distributiva}

Los efectos distributivos del crecimiento de la producción de biodiésel en la Argentina deben ser analizados a partir de su repercusión en el sector agrícola. Uno de los primeros efectos distributivos de esta expansión se encuentra en el desplazamiento relativo de los pequeños productores, quienes ante la presencia de grandes inversores y el aumento del precio de la tierra deciden alquilar y dejar de producir. Este último aspecto repercute también en el empleo rural (Giarraca y Teubal, 2005; Honty y Gudynas, 2007; Biodiversidad, 2007). De acuerdo con estimaciones de diversos autores, la mecanización e introducción de la soja transgénica en el país ha implicado el desplazamiento de al menos 200.000 pequeños productores entre los años 1990 y 2001 , lo que se relaciona con la necesidad de disminuir los costos de producción del biodiésel para hacer más competitivo el combustible. Sobre la base de información de la CEPAL (2011) y Botta y Selis (2003), la mecanización y el método de siembra directa implementado en la Argentina reducen los requerimientos de horas/hombre, implicando una pérdida de cuatro de cada cinco empleos.

En el Brasil, a pesar de los esfuerzos realizados por el gobierno para favorecer a la agricultura familiar, la mayor parte de la producción de biodiésel tiene como materia prima la soja proporcionada por grandes productores. Naturalmente, este hecho tiene implicancias directas en el alcance de las metas sociales y ambientales. Más del 90\% del biodiésel proviene de la soja o del sebo bobino. Es posible que apenas el $20 \%$ del biodiésel producido en el país provenga de la agricultura familiar, del cual el $90 \%$ corresponde a cultivos de soja de agricultores familiares, normalmente del sur o del centro-oeste del país. Lamentablemente, estos agricultores no corresponden a los segmentos más empobrecidos de la agricultura, que constituían la población de origen del PNPB.

Sin embargo, el número de agricultores integrados a la cadena del biodiésel crece, en gran medida debido a la entrada de las tres plantas de Petrobras y a la creación de Petrobras Biocombustível (PBio), que se constituye como la mayor empresa que compra oleaginosas a la agricultura familiar en la zona semiárida del noreste del Brasil.

Es fundamental reconocer que gran parte de las esperanzas relacionadas con el alcance de las metas sociales y ambientales del PNPB recaen en la gestión operacional, financiera y logística de PBio, empresa que posee suficientes recursos políticos, financieros y humanos para cargar con parte de los costos de la cadena de abastecimiento e impulsar a la agricultura familiar y vitalizar las metas sociales y ambientales de la política del biodiésel en el Brasil.

Empero, los sectores ligados a la agricultura familiar demuestran preocupación y dudas en cuanto a la eficiencia de los instrumentos de la nueva política. Para ellos, la inclusión de la agricultura familiar se encuentra lejos de estar consolidada y existe un elevado riesgo de que esta política funcione como un modelo tradicional de integración entre la agricultura familiar y la agroindustria. Estos sectores defienden como alternativa un modelo de producción más descentralizado, en el que los agricultores familiares cuenten con un mayor apoyo de las empresas y del Estado para poder en el largo plazo avanzar hacia la oferta del aceite vegetal en lugar de la oleaginosa (véase el gráfico 8).

GRÁFICO 8

Brasil: número de familias proveedoras de materia prima, 2005-2010

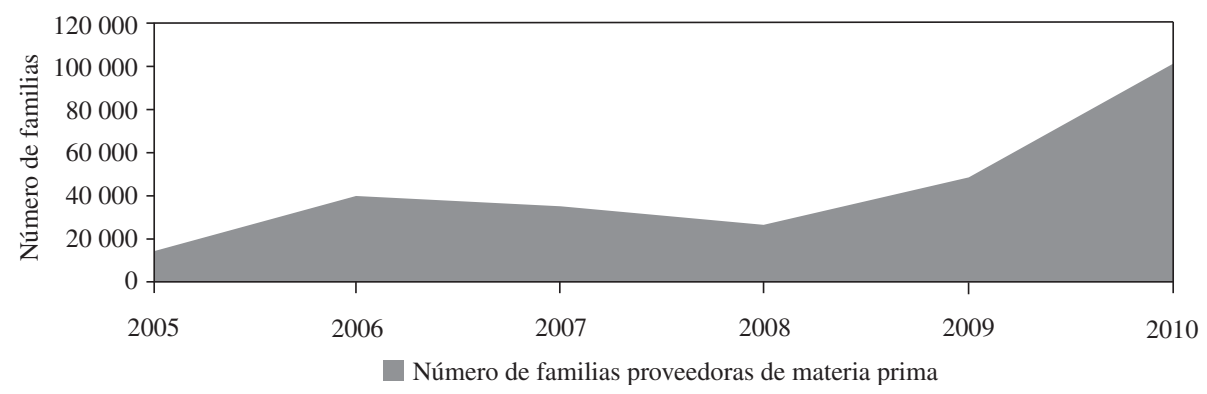

Fuente: elaboración sobre la base de Ministerio de Desarrollo Agrario y G.M. Senatore y otros, "O biodiesel e sua contribuição ao desenvolvimento brasileiro", Fundación Getulio Vargas y União Brasileira do Biodiésel, octubre de 2010 [en línea] http://www.ubrabio.com.br/ sites/1700/1729/00000201.pdf. 


\section{V}

\section{Reflexiones finales}

La comparación entre los casos de la Argentina y el Brasil exige el reconocimiento inicial de los distintos contextos político-económicos y de los diferentes motivos que han impulsado en uno y otro país la regulación del biodiésel. En ambos casos, la política de incentivo a la producción data de inicios de la década de 2000. Sin embargo, desde entonces las trayectorias de los mercados del biodiésel presentan divergencias en ambos países.

En el caso de la Argentina, el impulso se ha relacionado principalmente con la necesidad de realizar un aporte en la búsqueda del autoabastecimiento en el sector energético, que desde el año 2004 enfrenta una considerable crisis, agravada en los últimos años por la caída en las reservas de hidrocarburos y la capacidad de producción de las refinerías. De esta forma, uno de los aspectos que han promovido el aumento del corte obligatorio de un $5 \%$ a un $7 \%$, con grandes perspectivas de incrementarse al $10 \%$ hacia finales del año 2012 e incluso hasta el 20\% para algunos sectores como el transporte de pasajeros o el sector agrícola, ha sido la necesidad de reducir la creciente importación de gasóleo. Estas importaciones se han visto potenciadas en los últimos años por la creciente demanda desde el sector eléctrico, que también se encuentra al tope de su capacidad instalada y con serios problemas de abastecimiento de su principal combustible, el gas natural. En este sentido, el biodiésel puede constituir un aporte a este sector mediante la instalación de plantas de generación sobre la base de biocombustibles, especialmente luego del lanzamiento del programa GENREN, así como de otros programas de abastecimiento eléctrico ${ }^{23}$.

\footnotetext{
23 Este es el caso, por ejemplo, del programa Energía Plus puesto en marcha en el año 2006 mediante la Resolución 1281/2006. De acuerdo con diferentes analistas de la industria energética argentina, este programa obliga a los grandes usuarios a obtener por su cuenta la cobertura de las mayores demandas eléctricas que consuman respecto del año 2005, al tiempo que genera un negocio adicional para los potenciales productores. Tal como lo establece la resolución, el Servicio Energía Plus, consiste en la oferta de disponibilidad de generación adicional por parte de agentes generadores, cogeneradores o autogeneradores que no fueran agentes del Mercado Eléctrico Mayorista (MEM), no contaran con las instalaciones de generación, o no se encontraran interconectados al MEM. De esta forma, estas nuevas inversiones en Servicio Energía Plus quedan sujetas a negociación entre los grandes usuarios y los proveedores, los que pueden establecer contratos con términos, condiciones y precios determinados particularmente.
}

Detrás de las motivaciones energéticas se encuentran las motivaciones relacionadas con los intereses del sector agrícola. En la zafra 2009-2010, el país produjo casi 54,5 millones de toneladas de soja. Los intereses de este sector quedan claros al analizar su papel en el proceso de formulación de la política energética, la búsqueda de mayores incentivos fiscales y la actual tendencia a la participación de algunos de los principales productores de soja en plantas elaboradoras del biodiésel.

En el Brasil, por otra parte, la política del biodiésel ha ganado impulso a partir del año 2000, y la experiencia anterior ha sido decisiva en el momento de la elaboración del plan de promoción. Así, el programa Pró-Álcool ha jugado un papel fundamental al mostrar éxito desde el punto de vista energético, pero un fracaso desde la perspectiva social. Por tales motivos, en la política brasileña del biodiésel se incorporan en forma explícita los objetivos sociales. Dicha política ha abierto, además, un espacio para el movimiento de las organizaciones de la sociedad civil en el debate de la política energética que hasta el momento se encontraba restringido a aspectos técnicos.

Dado el breve tiempo transcurrido desde la puesta en marcha de las políticas, los resultados alcanzados por cada uno de los países no pueden ser completamente evaluados en la actualidad. Sin embargo, a priori se observan diferencias. De acuerdo con los datos aportados por fuentes oficiales, la Argentina parecería transitar en su matriz hacia una mayor sustitución por biocombustibles del diésel oil y el gasóleo, y en cierto grado la política pública argentina de incentivo al biodiésel podría ser considerada exitosa. Sin embargo, en este país la producción de biocombustibles se halla altamente orientada al mercado externo, y el sector exportador - formado por grandes grupos empresariales - no se encuentra dentro de la población objetivo de la política y por ello no se ve beneficiado por los incentivos. En consecuencia, la expansión de la capacidad productiva del biodiésel obedece más directamente a la dinámica de crecimiento del mercado mundial de soja y al régimen tributario nacional en torno de las exportaciones de los subproductos, que ha tornado relativamente más atractivo al biodiésel que el grano o el aceite. En este sentido, el mercado del biodiésel argentino se divide en dos 
grupos, las grandes aceiteras orientadas al mercado internacional que han convertido a la Argentina en el mayor exportador mundial de biodiésel, y los pequeños productores restringidos al mercado nacional mediante el cumplimiento de las metas obligatorias.

De esta forma, el objetivo explicitado en la legislación de promover los pequeños emprendimientos no parece cumplirse. Una de las posibles explicaciones de la mayor presencia de grandes industrias y de la preferencia por la exportación radica en que los incentivos económicos propuestos en la legislación no son suficientes. En un contexto de precios distorsionados de los combustibles y con el establecimiento de retenciones a las exportaciones relativamente menores en los biocombustibles, la producción de biodiésel para su exportación constituye la opción más rentable para los productores.

Por el contrario, en el Brasil el motor del crecimiento del mercado del biodiésel ha sido el mercado interno, cuyo ritmo se encuentra determinado por el Estado a través del Consejo Nacional de Política Energética (CNPE). La creación de un mercado interno garantizado y los incentivos fiscales otorgados por la nueva legislación han logrado que los grupos productores de biodiésel, así como los grandes productores de soja, se hayan volcado al mercado interno a través de las subastas establecidas por el gobierno. En tal sentido, es posible afirmar que los instrumentos utilizados en la política han sido exitosos para garantizar la oferta y evitar el riesgo de desabastecimiento del mercado local. Al mismo tiempo, el Brasil parece estar logrando disminuir la importación de diésel, lo que reforzaría el cumplimiento de los objetivos del programa.

No obstante, la participación de la agricultura familiar dentro del PNPB es muy marginal, y la soja se constituye como el principal insumo de la producción de biodiésel. En efecto, la experiencia reciente pone en evidencia que las deficiencias estructurales en parte de la agricultura familiar del país ${ }^{24}$, tales como la dificultad de acceso a recursos, a la tecnología y al capital, se constituyen en un claro limitante para el avance del programa.

Pese a ello, en el caso brasileño se destaca la presencia de Petrobras Biocombustível como uno de los dos actores más importantes en la búsqueda de la consecución de los objetivos sociales y ambientales del PNPB. El carácter semiestatal de esta empresa le permite encontrar, más allá de los objetivos netamente empresariales privados, objetivos sociales coincidentes con la política energética brasileña de acuerdo con las prioridades del gobierno federal.

Sin lugar a lugar a dudas, las diferencias más claras entre la Argentina y el Brasil en torno de los resultados alcanzados por cada uno de estos países en relación con los objetivos de los programas, se han relacionado en cada caso con la madurez de las políticas energéticas, la experiencia, y sobre todo la existencia en Brasil de una empresa como Petrobras, que puede ser utilizada por el Estado nacional para implementar y direccionar en forma más nítida los objetivos de la política energética, aspecto que ha sido inexistente en el caso argentino. No obstante, a inicios del año 2012 el Estado argentino decidió retomar el control sobre la principal compañía energética argentina, YPF S.A. ${ }^{25}$, privatizada veinte años atrás. En este sentido, el uso de esta empresa como herramienta de política energética podría eliminar las diferencias entre ambos países en torno a los senderos seguidos por los mismos y al alcance de los objetivos planteados en la política.

\footnotetext{
${ }^{24}$ En especial la del nordeste del Brasil.

25 De acuerdo con la Ley $N^{\circ} 26.741$, publicada en el Boletín Oficial el día 7 de mayo de 2012, y su Decreto regulatorio $N^{\circ}$ 660/2012, la composición accionaria de YPF S.A. se distribuiría de forma tal que el $26 \%$ pertenece al Estado nacional, el $25 \%$ a estados provinciales y el resto se distribuye en accionistas nacionales e internacionales y cotización en la bolsa. Información disponible en: www.infoleg.gov.ar
}

\section{Bibliografía}

ANP (Agencia Nacional de Petróleo, Gas Natural y Biocombustibles) (2011), Boletim mensal de biodiésel, Río de Janeiro.

BID (Banco Interamericano de Desarrollo) (2006), La política de las políticas públicas. Progreso económico y social en América Latina, Informe 2006, Washington, D.C.

Biodiversidad (2007), $\mathrm{N}^{\mathrm{o}}$ 52, abril [en línea] http://www.grain.org/ biodiversidad $/$ type $=47 \& \mathrm{l}=0$ ]

Botta, G. y D. Selis (2003), "Diagnóstico sobre el impacto producido por la adopción de la técnica de siembra directa sobre el empleo rural. Una Recopilación. Brasil. Lei № 11.116 de 18 de maio de 2005 ".
Bureau, J.C. y otros (2006), "European biofuel policy: how far will public support go?", Handbook of Bioenergy Economics and Policy, M. Khanna y otros (orgs.), Springer.

CADER (Cámara Argentina de Energías Renovables) (2010), Estado de la industria argentina de biocombustibles. Comienza el mercado nacional de biodiésel y bioetanol, Buenos Aires, mayo.

CEPAL (Comisión Económica para América Latina y el Caribe) (2011), "Estudio regional sobre economía de los biocombustibles 2010: Temas clave para los países de América Latina y el Caribe", Documento para discusión, Santiago de Chile, marzo. 
Chidiak, M. y L. Stanley (2009), "Tablero de comando para la promoción de los biocombustibles en Argentina", Documentos de proyecto, $\mathrm{N}^{\circ} 242$ (LC/W.242-P), Santiago de Chile, febrero.

EPE (Empresa de Pesquisa Energética) (2010), Balanço energético nacional 2010: ano base 2009, Río de Janeiro.

Galperín, C. y C. Pérez Llana (2009), "Desarrollo de los biocombustibles, interrelación de políticas y opciones de política comercial", Revista argentina de economía agraria, vol. 11, № 1, Buenos Aires, Asociación Argentina de Economía Agraria.

Giarraca, N. y M. Teubal (2005), El campo argentino en la encrucijada. Estrategias y resistencias sociales, ecos en la ciudad, Buenos Aires, Alianza Editorial.

Honty, G. y E. Gudynas (2007), Agrocombustibles y desarrollo sostenible en América Latina y el Caribe. Situación, desafios y opciones de acción, Montevideo, Centro Latino Americano de Ecología Social (CLAES)/Desarrollo, Economía, Ecología y Equidad América Latina (D3E).

Khanna, M., J. Scheffran y D. Zilberman (2006), "Bioenergy economics and policy: introduction and overview", Handbook of Bioenergy Economics and Policy, M. Khanna y otros (orgs.), Springer.

Lima, P.C.R. (2005), Biodiésel: um novo combustível para o Brasil, Cámara de Diputados, Brasilia.

Ministério de Minas y Energia (2010), Balanço energético nacional, 2010, Brasilia.

(2006), Balanço energético nacional, 2006, Brasilia.

Msangi, S., M. Ewing y M. Rosegrant (2006), "Biofuels and agricultural growth: challenges for developing agricultural economies and opportunities for investment", Handbook of Bioenergy Economics and Policy, M. Khanna y otros (orgs.), Springer.

OLADE/CEPAL/GTZ (Organización Latinoamericana de Energía/ Comisión Económica para América Latina y el Caribe/ Sociedad Alemana de Cooperación Técnica) (2003), Energía y desarrollo sustentable en América Latina y el Caribe: Guía para la formulación de políticas energéticas (LC/G.2214-P), Santiago de Chile. Publicación de las Naciones Unidas, $\mathrm{N}^{\mathrm{o}}$ de venta: S.03.II.G.160.

Pistonesi, H. y otros (2008), "Aportes de los biocombustibles a la sustentabilidad del desarrollo en América Latina y el Caribe: Elementos para la formulación de políticas públicas", Documentos de proyecto, $\mathrm{N}^{\circ} 178$ (LC/W.178-P), Santiago de Chile, Comisión Económica para América Latina y el Caribe (CEPAL).

Recalde, M. (2012), "Los recursos energéticos en Argentina: Análisis de la renta", Problemas del desarrollo. Revista latinoamericana de economía, vol. 43, No 170, México, D.F., Universidad Nacional Autónoma de México.

(2011a), "Energy policy and energy market performance: the Argentinean case", Energy Policy, vol. 39, N 6, Amsterdam, Elsevier.

(2011b), Sistemas energéticos, mercado y Estado. El rol de los recursos naturales energéticos y la política energética en el caso argentino, Madrid, Editorial Académica Española.

(2011c), "Determinantes de la inversión en exploración de hidrocarburos: Un análisis del caso argentino", Cuadernos de economía, vol. 34, № 94, Madrid, Universidad Complutense de Madrid, enero-abril.

(2010), "Sistemas energéticos y desarrollo socio económico: Implicancias del control sobre los recursos naturales energéticos", tesis doctoral, Bahía Blanca, Universidad Nacional del Sur.

Senatore, G.M. y otros (2010), "O biodiésel e sua contribuição ao desenvolvimento brasileiro", Fundación Getulio Vargas y União Brasileira do Biodiésel, octubre [en línea] http://www.ubrabio. com.br/sites/1700/1729/00000201.pdf.

Timilsina, G.R. y A. Shrestha (2011), "How much hope should we have for biofuels?", Energy, vol. 36, № 4, Amsterdam, Elsevier. 